\title{
Perception towards Family Planning and its Implication to Environmental Sustainability: The Case of two Selected Kebeles in Aroresa Woreda in Sidama Zone, Ethiopia
}

\author{
Zenebe Shuite Argado \\ Department of Geography and Environmental Studies, Bule Hora University lecture, Ethiopia
}

\begin{abstract}
This study was conducted aiming at to assess perception of couples towards family planning and its relevance to environmental sustainability and to identify factors hindering family planning practice. Sample respondents for study comprises 90 couples in rural and 28 in urban. Data was collected by using random systematic and simple random sampling methods. The instruments used for data collection were interview and focus group discussion. The research found that there is promising level of awareness on family planning and main source of information were health extension agents.

Reported reasons in sought of large number of children were old age support, son or daughter preference, considering children as a wealth, and labor support, religious prohibition. Nearly half of respondent couples approve contraceptives with more approval of women in both settings. Most of the respondents showed positive attitude towards family planning. Furthermore, half of the rural and nearly less than half of the urban respondents approve the importance of family planning for environmental sustainability. During the study period $23.2 \%$ of urban and $18.9 \%$ of rural couples were using some method of family planning; among which 21.4 of urban and $16.7 \%$ of rural women were using modern methods, hence, awareness level and practice in family planning showed a gap in both urban and rural. In general, urban showed more favorable attitude and practice than rural couples in family planning. Despite of their lower practice in family planning, rural respondents likely showed more favorable attitudes towards relevance of family planning for environmental sustainability.
\end{abstract}

Keywords-Environment, Family planning, Perception, Population.

\section{INTRODUCTION}

Fertility is the most important component of population dynamics and plays a major role in changing the structure of the population of a given area. And this high fertility is main factor for rapid population growth in developing countries. Population increase exerts pressure on land recourses and contributes to the loss of its productive capacity. The degradation of the natural resources of the environment has serious economic and environmental consequences (Bekure and Singh, 1996). An increasing population density leads to a greater depletion of rural community resources like fire wood, water and soil... furthermore, poverty, environmental degradation and high fertility drive one another in a vicious cycle (Wright, 2008).

There have been the two contrasting views concerning rapid population growth on one side and food supply, resource use, economic development and environmental quality issues on another. The two contrasting arguments on these issues have long history, $18^{\text {th }}$ century, age of Thomas Robert Malthus and thereafter by the opponent of him was Ester Boserup. The main contends of Malthus in "Limit to growth" were that the growth of world population at the time at $2 \%$ per annum was rapidly endangering man kinds ability to feed itself, that some of the world's non renewable resources were about to be exhausted, and that even if we managed to avoid these two dangers, we would pollute choke to death. Assuring the problem of rapid population increase, he suggested some solutions to reduce population growth that are people would have to die whether starvation, or of pestilence, or of war as positive check. Another alternative he expressed were moral restraints such as postponing marriage and absistences as negative checks (Neurath, 1994). On the other hand, Boserup 1965, believed that people have the resources of knowledge and technology to increase food supplies for ever growing population. She advocates that population growth (pressure) led to innovation and more production in agricultural activity rather than being cause of problem.

However, beyond her suggestions of satisfying food supply, there are also environmental implications of rapidly growing population and in the application of such technologies. In her view, population growth might have a 
positive influence on the productivity of the environments as population increase demands for food increase, follow periods shorten and crop production increases, but, this situation cannot be free of environmental degradation since rate of exploitation of the natural environment is intensifying. According to Malthusians view, the environment is likely a gas bottle, with a fixed ability to absorb human activity. This fixed ability is termed as carrying capacity of a resource, pushed beyond that point of ability, it degrades very rapidly, similar to a container buckling or exploding under pressure. Contrastingly, Boserupians conception is that the environment is more like a balloon- its shape and capacity is actually changed as pressure builds up. Carrying capacity is, therefore, not fixed but can be influenced or shaped by the application of labor and technology (Sarre and Blunden, 1995).

But, today in most of developing agrarian countries, rapid population growth along with unsustainable use of resources, have remain one of the hindering factors for economic development, led to poor social conditions and environmental degradation. Todaro has stated features of developing countries asdeveloping countries denote those areas having low and slowly growing per capita income, poor health, condition, high rate of illiteracy, pronounced income disparities, Substantial dependency on small scale agriculture and primary product (Todaro, 1981). Hence, Most of the sub-Saharan African countries can be cited as prime examples of this phenomenon. Being a developing and one of sub Saharan countries, Ethiopia is characterized by such rapid population growth, small scale agriculture, low per capita income, and food insecurity.

The emergence of families having no farmland in typical rural areas, of Ethiopia, was a clear sign of the ever increasing imbalance between available farmland and the population (Getu, 2009). Consequently, recognizing the associated problems of rapid population growth on the socio-economic development and environment, the government of Ethiopia has recently begun giving due consideration integrating population variables in the development planning processes.

In with this line, Family planning is considered as one of the important means in controlling undesirable population growth particularly in such conditions of imbalances between population and available resources and population growth induced environmental degradation. Strengthening family planning facilities and promoting the information dissemination and population issue education are essential instruments in regulating rapidly growing population of the country.

Concerning researches progress on issues of family planning, family size and quality of life, and relation of fertility and environmental degradation, some researches have been conducted. For instance, Joekes, S (1994) entitled "Children as a Resource: Environmental Degradation and Fertility" through several case studies in developing countries, who concluded that Environmental pressures are just one of several economic factors that may influence reproductive decisions... Sometimes the counteracting facts which lead women on the one hand to desire more children and on the other to desire fewer, are so balanced as to cancel each other out, and result in no actual influence on desired fertility levels; Haq, A etal(2010) "Perception, Environmental Degradation and Family Size Preference: a Context of Developing Countries" who concluded that People perception to environment and family size is very important to use contraception. People who perceive their immediate environment is declining will use contraceptive than those who do not perceive environment as declining. If people perceive that their environment is degrading for excessive access into the natural resources, they may adopt to use contraception and reduce family size.

Giving the above assertion on the problem of rapid population growth, there is needed to investigate perception of couples towards family planning as it is the way to optimize population growth. The problem of imbalance between rapidly growing population on one side and economic development, natural resource degradation, food insecurity on the other side, and the absence of research conducted in particular to the current study area in relation to family planning and environment, are deriving forces to conduct this research.

\section{METHODOLOGY OF THE STUDY}

\subsection{Study Population and design}

The design of this study is cross sectional so as to collect data at a point of time. Study population is residents of two selected kebeles (local smallest administrative unit in Ethiopia) namely Saddeka kebele, and Girja town (Girja kebele includes urban and rural parts), in Aroressa Woreda (district), SNNPR. The Couples, men and women, in terms of household units are the target population of this study in the above mentioned kebeles. The source of population data obtained from documents of respective kebele offices. Based on this information, currently, residents of household units are 895 for Sadeka, and 281 for Girja town.

\subsection{Sampling technique and sample size}

The study kebeles were purposively selected because of proximity of rural and urban areas for data collection process and they are among those environmentally suffered kebeles. Before get into process of data collection, the study areas were divided into geographical strata with due consideration of the number of housing units, this was done to avoid possibility of exclusion and/or to enhance 
chance proportionally for all areas of the study settings. Based on this, rural kebele was divided into 10 geographical strata whereas urban area into 4 strata. From each of the study kebele, 10 percent of couples were made participated for interview, since method itself is time and budget consuming. In addition to this, assuming that, most probably the study population in each of their respective settings has homogeneous socioeconomic characteristics. To select the subjects or couples by their housing units, random systematic sampling method was employed, and by doing this every $10^{\text {th }}$ house was selected starting from edge of already subdivided stratum. The quota was already assigned for each stratum. Hence, 90 couples from rural areas and 28 couples from urban were selected and participated in the interview. The subjects of the study were couples (women and men), if either of the selected or both of them are not volunteer, interviewer pick next house within the stratum, until desired number of subjects would achieved. In case of polygamy, men with their younger women (if reluctant with the elder one) since younger one has more reproductive span, were interviewed.For group discussion, 4 sessions for each study settings were arranged and scheduled. Each group consists of 8 members for rural (32 individuals) and 4 members for urban (16 individuals) with equal involvement of women and men. Participants of discussion were selected by simple random sampling or lottery method and proportionally from all areas of the study and discussion within group averagely took about 2 hours.

The age of women who participated in the study range from 15 to 49 , as it is fertility life span for women.

\subsection{Instrument of data collection}

In order to gather realistic information for stated objectives of the study, two types of data collection instruments were employed. Structured questionnaire for interview and guidelines for group discussion, health extension workers and for health offices interview, were prepared. And local language, Sidama, version of the questionnaire was used for data collection. Some of the questionnaires are adapted from 2000 Ethiopian Demographic and Health Survey, and some of the questionnaire were prepared by researcher himself based on the reviewed literature. In order to get correction on interview and discussion results the tape recorders were used.

\subsection{Data collection procedures}

The Author has recruited 5 nurse diploma new graduates of private colleges, 2 males and 3 females, who are residing in the study areas and this enables easily data collection as collectors are familiar with the areas. Including the author totally 6 data collecting persons. They were chosen because of their familiarity with the concept of family planning. During interview male and female data collectors interviewed their respective gender, this was done so as to avoid fear for respondents and to enhance free expression of their idea. Data collectors were given appropriate training for two days on the objectives of the study and on the detailed issue of the each part of the questionnaire. In specifically, training consists of objective of the study, introduction of questionnaire format, procedure of interviewing, issue of privacy and consents of respondents.

Group discussion sessions were undertaken among women and men in their respective gender grouping, and every group was assisted by their respective gender of data collectors. This was done so as to promote free expression of ideas for participants. Researcher did an interview with health extension worker, woreda health office and Girja health center to get supplementary data.

\section{5 Methods of data analysis}

The data was collected through interview and focus group discussion. Moreover, it was analyzed by using both quantitative and qualitative methods. Frequencies, percentage distribution and mean were applied to summarize the results.

\section{LOCATION OF THE STUDY AREA}

Aroresa Woreda is found in SNNPR and southern part of the Sidama zone. The study kebeles, particularly, located in the western part of the Woreda. According to WIDS,2007, the absolute location of the woreda is about between $6^{\circ} 4^{\prime} 45^{\prime \prime} \mathrm{N}$ and $6^{0} 26^{\prime} 30^{\prime \prime} \mathrm{N}$, and $38^{\circ} 54^{\prime} 50^{\prime \prime} \mathrm{E}$ and $39^{0} 12^{\prime} 30$ '"E

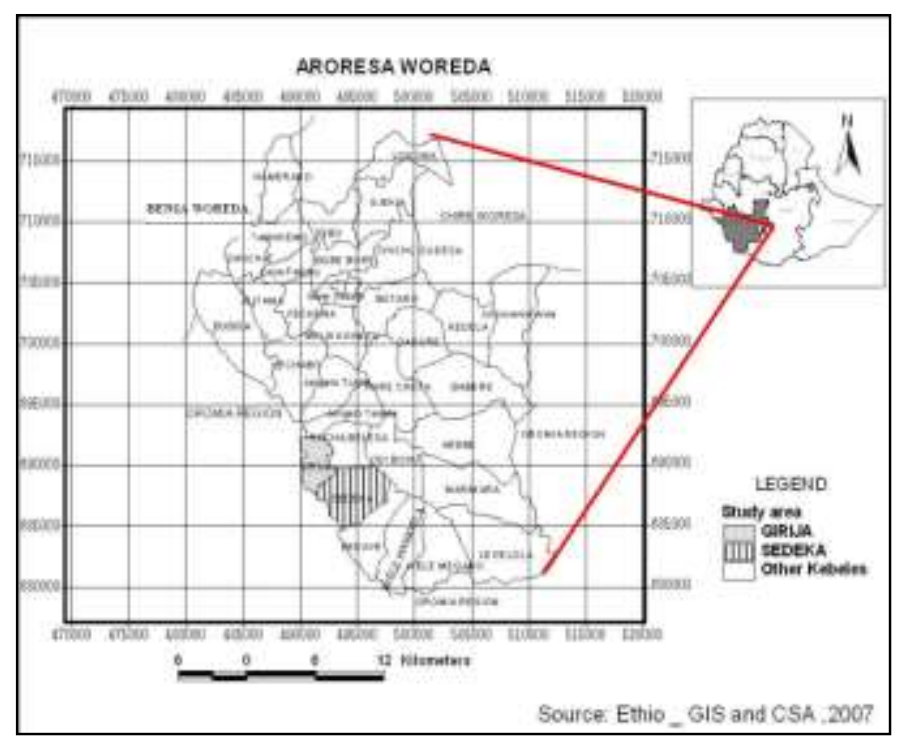

3.2 Health services in the Woreda

According to the Woreda health office, the government health facilities in Aroresa Woreda includes 4 health centers( Girja, Mejo, Kinkamo and Wele magado), 25 
health posts in 22 peasant associations ( some of them are not functioning currently), 8 private drug shops.

The study kebeles that are Girja and Sadeka are found adjacent to each other. As mentioned above Girja kebele which includes urban and rural parts has one health center and four private drug shops whereas Sadeka kebele has one non-functioning health post. But each of these study kebeles have two health extension workers who have been playing important role in different areas of health extension programs in which family planning is one of the areas of the services.

\subsection{Environmental conditions}

According to WIDS (2007) document, in the Woreda there is great threat resulting in loss of natural vegetation cover that occurred by is ever existing demand for farm land and human encroachment. Wildlife of the Woreda is limited to few common wild animals; the sustainability of the resource is threatened by deforestation, settlement encroachment and illegal hunting. Furthermore, land degradation has occurred that resulted from deforestation, agricultural depletion and settlement conversion. This all are mostly consequences of increasing in population density. Although, no particularly written document about study kebeles, from my experience by living long, about 15 years, in the area it important to say something about study areas. Being situated in the drought prone areas of the Woreda these kebeles reflect more sever features what is stated above. Forests are cleared for agricultural activities and soil erosion is become increasing.

\section{PRESENTATION AND DISCUSSION OF RESULTS}

The data for this study was collected both from rural and urban areas of two selected kebeles. From one rural kebele, the data gathered from 90 Couples ( 90 women and 90 men) and from urban area 28 couples were selected and participated for interview. In addition focus group discussion among couples also undertaken, to obtain supplementary data health center office and health extension workers were interviewed. The information gathered comprises some of the socio- Economic and demographic characteristics, awareness about family planning, attitudes towards family planning and its implication to environmental sustainability, and practices in family planning.

\subsection{Socio economic and Demographic Characteristics of Respondents}

The data collected in this study reveals that most of respondent women have married in rural and urban below 18 years with mean of 16.5 and 17.5 respectively while mean age at marriage for rural men is 24 and for the urban
25 years. In both urban and rural the age at marriage for women was founded low, however, the urban late by one year. Regarding age at first birth in rural area, $79(87.8 \%)$ of respondent women have bore their first child at the mean age of 18 years while majority of men, 44 (48.9\%), bore their first child at the mean age of 25 years. Whereas in urban, $24(85.7 \%)$, of women reported that they have bear their first child at the mean age of 19 years. And 15 $(53.6 \%)$ of men bear first child in the mean age of 26 . Many studies in developing countries revealed that early marriage is one of the major factors that contribute to bear many children in reproductive life span particularly for woman. Average number of living children varies for rural and urban settings and at the same time also it differs for women and men. Mean number of children is 4.8 for women and 6 for men in rural while 4 for women and 5 for men in urban. Men have more average number of children; this is evident that the study areas are known by polygamy that enables men to have more children than their women. The mean age of respondent women is 28 for rural and 29 for urban. By having these sizes of children at this age level, in their reproductive life span they possibly could bear large number of children.

In terms of educational attainment, nearly less than half of the rural respondent women cannot read and write though most of general couples reported lower level of education that is primary and below which constitutes $88.3 \%$ for rural and $64.2 \%$ for urban couples. Consequently, low level of education may negatively affect the perception of couples towards family planning. Haq, A etal(2010) stated that since educational process makes more information available to women and may expose them to increase understanding about the family size, environmental degradation, their children's health, further educational opportunities and contraceptive use. Usually educated women may prefer to get married educated men who will be more positive to contraceptive use and lower family size.

Concerning couples occupation in rural, 85 (94.4\%) of women and $83(92.2 \%)$ of men were housewives and farmers respectively. In urban, most of women again, 19 $(67.8 \%)$, were housewives and $13(46.4 \%)$ of men were merchants. If women are busy with work out of home or employed worker they give less priority to bear many children otherwise being homemaker perhaps most women are encouraged to have large number of children.

Regarding religion most of, 85 (94.4\%), women and 86 $(95.6 \%)$ of men were protestants Christians in rural settings. In urban also the majority, $23(82.2 \%)$, of both women and men were protestant Christians. Religion has its implication towards family planning, in case of Christianity most of the time followers believe in the command of God (that says multiply in the earth) means 
no need of controlling birth and against this is considered as disobey to God.

\subsection{Awareness of family planning}

According to data obtained from survey, most of the respondent couples, $90.5 \%$ of rural and $98.2 \%$ of urban, were informed about family planning. Traditional methods in rural and pills in urban are the most known methods, however, pills, injectables and traditional methods are nearly equally known. Besides, in group discussion, $96 \%$ of urban and $89 \%$ of rural couples aware of family planning. The major sources of information in both rural and urban are health extension agents (workers) which accounts $73.6 \%$ for rural and $63 \%$ for urban spouses that followed by friends. The most reported sources of family planning services were also health extension agents, $81.6 \%$ for rural and $76.3 \%$ for urban couples. This implies that HEA are playing important role in family planning activities than other service providing centers. Majority of the respondent couples, $81.6 \%$ of rural and $61.8 \%$ of urban, responded that child spacing help for health of mother and children. Furthermore, though an a awareness and/or knowledge of family planning methods is prerequisite before practicing of family planning, it is impossible to say all those who know these methods can adopt them. And aware of it means not mean that an individual know how to use it. Therefore, based on the information obtain it can be concluded that spouses in the study areas are well aware of family planning and its methods.

\subsection{Attitudes towards family planning}

Currently, Eight-four percent of rural and eighty percent of urban spouses want more children than they have now. The mean desired number of children was 9 for rural and 6.7 for urban couples. In both settings, men have more level of fertility desire than women do. This is possibly because of children serve as labour force especially in rural areas. Consequently, higher level of desired number of children is driving force for couples to produce large number of children until they achieve targeted size in their reproductive life span.

The reported reasons of wanting many children for most of the respondents is old age support, which followed by having few children and want sons. Group discussion participants also responded similar reasons adding that children help them in labor in rural settings. Contrastingly, in both settings, a few of the respondents not want more children and their reasons were because of economic problem, for seek of family welfare, to promote the health of mother and children.

Sixty eight percent of urban and sixty two percent of rural spouses approve preventing pregnancy. And $62.5 \%$ of urban and $53.9 \%$ of rural also approve modern contraceptives, with more approval of women than men, however, when results presented in terms couples, it does not indicate that both men and women of the same couple do approves, but, it shows either of the spouses or both of them approving because it is average total of the womenmen results. Here women more approve controlling birth and using contraceptives than men. This may because of women being victims of birth risks and they have more access to information of family planning through health extension agents. Besides, it is also important to identify whether spousal partners know approval of contraceptives by their spouses. $36 \%$ of the rural and $50 \%$ of urban couples reported that they know that their spousal partners approve using modern contraceptives while $53.9 \%$ of rural and $41.1 \%$ of urban spouses do not know whether their partners approve using contraceptives. This indicates that there may no further communication about family planning between women and men though urban couples showed better result than their counterparts.

Unsurprisingly, $31.1 \%$ of rural men believe that using contraceptives causes loss of loyalty between women and men while only $10 \%$ of women supporting the same view. $35.7 \%$ of men and $17.8 \%$ of women in urban also have the same view, with higher percentages of men than women supporting the idea.

Most of respondents in both sittings showed favorable attitudes on the advantages or benefits of child spacing, family planning for all members of a family and for health of mother and children. Majority of them also believe that discussion about family planning between spousal partners is important, and both wife and husband have responsibility when deciding family planning so as to fixing size of family. But a few of women do not accept the importance of discussion about family planning with men, this is because afraid of disapproval by their men if they discuss on the issue.

Concerning large family and its economic implication to family members, $81.7 \%$ of rural and $83.9 \%$ of urban couples agreed that larger family face more difficulty managing for food, clothing, schooling and health care than those smaller one. About $84 \%$ of urban and $80 \%$ of rural couples also in discussion have the same view. This implies that most of the couples were aware of the burden of large family despite socioeconomic factors enforce them to have many children. Regarding the issue of large family, several studies showed that larger family will result inability to function well and fulfill necessities for family members. For instance, Arthur (2009) wrote that households with smaller family size enjoy better social and economic life compared to those with relatively larger family size. However, $33.9 \%$ of urban and $42.8 \%$ of rural couples consider large number of children as a wealth. 
Some of the of respondent couples in group discussion also reported that many children may accompany with several lucks and they consider many children not only burden but also support for parents in different socio economic activities. This is also possibly related to several factors that some researchers have founded, for example, Goldwell 1982, quoted in Binyam, 2007, wrote that in sub Saharan Africa children are viewed as an investment in the future economic security. Having many children is considered as gains of prestige and status for the family in community.

The results of interview with health center and health extension workers showed that in the early years of their services, women's attitude towards family planning is not as such positive, most of them disapprove contraceptives by religious and traditional believes. But later on, through time attitudes of the most of women become favorable. As the information obtained from their women, most of the time aged men disapprove using contraceptives because of traditional believes and they need large number of children.

Moreover, $62.2 \%$ of rural and $76.7 \%$ of urban spouses have intension to use family planning in the future. In addition, nearly more than half of rural and three-fourth of urban spouses in group discussion reported they have desire to use family planning in the future with having more interest by women. This possibly shows that most of the couples have interest to use family planning and their attitudes are becoming favorable though actual use of family planning methods is low.

\section{4Attitudes towards relevance of family planning to sustainability of natural resources and environment}

This research includes assessing attitudes of men and women towards relevance of family planning to environmental sustainability. Regarding this attitude, about eighty percent of the respondents in both settings agree that rapid population increase can lead to over utilization of natural resources and large family may contributes to environmental degradation. Majority of respondents, $71.7 \%$ of rural and $71.4 \%$ of urban, also believe that family planning and/or contraceptive use can reduce family size and further pressure on the natural environment. Moreover, $52 \%$ of rural and $46.4 \%$ of urban spouses believe that people should use family planning to reduce family size for seek of sustainability of natural resources and environment. This indicates that most of the respondent couples were aware of the problems of rapid population growth to natural environment even if their use of family planning is founded as low, since existing socio cultural factor influence them to have large number of children.
Study in Kenya by Joekes, 1994, revealed that influence on fertility levels of Environmental pressure is mixed; pressure affects the general productivity of a dependent livelihood systems. Thus, the prevailing change in perception of the values of children is towards appreciation of their future income contribution. Therefore, environmental pressures have indirect effect of influencing women and men to desire a smaller family size.

The issues of population, environment and development are inter related and should be integrated as emphasized by the united nation strategies of environment, population and development. By considering the importance of empowering women for the sustainable development and environmental sustainability, the world Bank (1994) stated that investing proportionally more women than men- in education, health, family planning, access to land, inputs, extensions, is an important part of development that contribute environmentally sustainable development. It produces significant social gains lower fertility, better household nutrition, and reduced infant, child and maternal mortality. On the other hand, environmental degradation increases women's burden, as they trek long distances to fetch fuel wood, and water. Hence, empowering women promotes family planning and then family planning offers meaningful contribution to environmental sustainability by reducing rapid population increase thereby minimizing pressure on a natural environment particularity in developing countries. Because in developed countries the development of industries rather than population pressure, enables people to highly exploit natural environment and degrade it.

\subsection{Family planning practices}

Family planning practices, $54.4 \%$ of rural and $60.7 \%$ urban spouses means either of them or both of women and men have ever used some methods of family planning with highest percentage of traditional methods in both settings which followed by the two contraceptives that are pills and injectables, the least used method among three modern contraceptives was condom. However, majority of group discussion participants believe that contraceptives are more secure than traditional methods. About half of discussion participants, likely more in urban, reported that they have ever used some methods of family planning. Here it is necessary to note that except condom no other modern male methods of family planning so that whether the method is traditional or modern, men have reported methods as used that either they or their women used methods. Among purposes of using family planning child spacing is the most common one in both settings.

Some of the users of those methods have discontinued. Common reasons for discontinuation were want to have more children, religions prohibition, fear of side effects of 
contraceptives and spousal disapproval in order of highest to lowest. Similar reasons were founded from discussion in both urban and rural. Wanting more children is again major reason for never using family planning. In addition, some of respondents believe that children are gift from God and preventing pregnancy is considered as against will of God. Spousal communication about family planning is important tool to make joint decision between spouses. Couples discussion is better in urban (39.3\%) than in rural (27.8) since last 12 months. However, majority of participants in group discussion believe importance of discussion between spousal partners, few of the women, more in rural, afraid of disapproval of men.

Concerning relations between awareness and practice of family planning, 90.5\% rural and $98 \%$ of urban couples reported that they are aware of family planning but current use of family planning methods showed gap when compared to that of awareness. Hence, $23.2 \%$ of urban and $18.9 \%$ of rural couples were using some methods of family planning.

Still practice of family planning is low in the study areas though factors traced to variety of sources. In relation to schools' influence through students' education, it may be weak. It is obvious that today most parents send their children to school and these students have to learn issues of population and family planning. Probably, so it is believed that those students may have influence their parents to have few children if they would equipped with appropriate knowledge on the concepts of family planning and problems of rapid population increase.

Current prevalence of modern contraceptives for women is $16.7 \%$ for rural and $21.4 \%$ of urban. But average of the two settings is $19.0 \%$, most of them using injectable and pills. This is likely better than pervious national survey, 2005 , EDHS, in which $15 \%$ of women were using some methods of family planning with majority relying on modern contraceptives such as injectabel and pills. This may be due to time difference and the efforts made by government through health extension programs. However, contraceptive prevalence among couples is not such appreciable.

\section{CONCLUSION}

The major findings of the study are concluded as follows:

There is a promising awareness level of family planning in both urban and rural settings. And the main source of information for family planning was health extension agents. This implies that HEA are playing important role in family planning activities than other service providing centers.

The mean desired number of children is 11 for men and 7 for women in rural while 7.4 for men and 6 for women in urban. So the higher level of desired number of children is driving force for couples to produce large number of children until they achieve targeted size in their reproductive life span. The reasons for wanting many children are old age support, sex preference, labor support and considering children as sources of wealth. In other words, these are the socio cultural factors that hindering family planning practices. In addition, religious prohibition as common one and, others influence also included.

Regarding approval of contraceptives, $62.5 \%$ of urban and $53.9 \%$ of rural couples approve modern contraceptives with more approval by women than men in both settings. Women more approve controlling birth and using contraceptives than men. This may because of women being victims of birth risks and they have more access to information of family planning through health extension agents. However, some of the respondents, more men and few women believe that using contraceptive cause loss of loyalty between wife and husband.

In terms of relation between family size and family wellbeing, about eighty percent of both rural and urban couples believe that large family face more challenge than smaller one for their facility, even if other factors encourage them to desire large number of children. In general attitude items towards family planning, most of the respondents showed positive attitude, however, urban couples likely showed more favorable attitude than the rural one.

Regarding the views to relevance of family planning for environmental sustainability, about $71 \%$ of both urban and rural couples believe that use of family planning reduce population growth and further pressure on the natural environment. And nearly more than half of rural and nearly less than half of urban respondents believe the importance of family planning to reduce family size for seek of sustainability of natural resources and environment. In their attitude towards natural environment, rural couples likely have more favorable attitudes than their counterparts.

Concerning practices of family planning, $60.7 \%$ of urban and $54.4 \%$ of rural spouses have ever used some methods of family planning with highest percentage of traditional method. Pills, injectables and condom are the three contraceptives among ever used methods in their order from highest. Currently, $16.7 \%$ of rural and $21.4 \%$ of urban respondent women are using modern contraceptives in the study areas. However, nearly more than half of the respondents approve contraceptives. Therefore, there is a gap between awareness and practices of family planning, so all concerned bodies work to fill the gap as family planning useful not only for family welfare but also wellbeing of environment and ecosystem. 


\section{ACKNOWLEDGEMENTS}

Above all, I would like to praise my advisor Dr. YOHANIS G/ MICHAEL for his constructive comment, valuable guidance and persistent encouragement from the very inception to the final phase of my work. The role of Addis Ababa University is appreciable in facilitating work of this paper by allocating fund.

I extend my heartfelt thanks to all my research informants who were participated in the study by scarifying their time and those who assisted me in data collection. In addition, I want to express my lovely gratitude to family for their financial support.

\section{REFERENCES}

[1] Akililu, Dalelo (2010). Education for sustainable Development: Focus on Ethiopia: Teaching material. AAU.

[2] Anvar, R(1995). Attitude Iranian mothers towards family planning, family size and fertility. Thesis, University of Wollongong. http://ro.uow.edu.au/theses/1880, visited on January 1,2011

[3] Arthur, L (2009). Family Size and Quality of Life Nexus; case of Sunyani Municipality, Ghana http://www.openmeeting2009.org/pdf fiiles/pdf\%20papers/Arthur\%20Family\%20size.pf visited on January 8, 2011

[4] Bekure, W and Singh, N (1996) (eds). Population, Sustainable use of natural resources, and development in Ethiopia: proceedings of the first annual conference. AA and ORCMacro

[5] Binyam, Tesfaye(2007). Preference for sex, number of children and contraceptive use in rural Ethiopia, Thesis, AAU.

[6] Chowdhury, H(2004). Environmental Education for Sustainable development: Asian perspective. UNUIAS working paper No. 129, http://www.ias.unu.edu/binaries2/IESWorkingPaper1 29.pdf, retrieved on march 3,2011

[7] Endris, Abera(2007). An Assessment of the population and family life education in the secondary school curriculum of south Wollo zone. Thesis, AAU.

[8] Haq, A, etal.(2010). Perception, Environmental Degradation and Family size preference: A context of developing countries. Journals of sustainable development. Vol.3, $\quad$ No. 4 www.ccsenet.org/journal/index.php/jsd/article/downl oad/8544/6392. Retrieved on January 15, 2011

[9] Joekes, S (1994). Children as a Resource: Environmental Degradation and Fertility. Focus on Gender, Population and Reproductive rights. JSTOR, Vol.2, No.
http://www.jstor.org/stable/4030221?origin=JSTORpdf, Retrieved on January 14,2011

[10] Josephy, $\quad B(2006)$.Environmental $\quad$ Studies, $\quad 3^{\text {rd }}$ edition.Tata McGraw-Hill

[11] Markos, Ezra and Seyoum, G/sellasie(1998). (eds). Hand Book on population and family life education for secondary school teachers in Ethiopia. Institute of Curriculum development and research, AAU

[12] Munasinghee, M (1993). (ed). Environmental Economics and Natural Resource Management in developing countries. World Bank.

[13] Palmer, J and Neal,P ()1996. The Hand Book of Environmental Education. Routledge.

[14]Raj, K (2010). Attitude of couples towards family planning. Jammu and Kashimer, India. Journal of Human ecology. 30(1): 63-70

[15]Rao, K and Redy, S (2005). Environmental education. Common Wealth.

[16] Ruth, G/Silasie (2006). Magnitude and Determinants of unmet need and barriers of family planning (among wives, husbands and couples) in Inderta district, Tigray region. Thesis, AAU.

[17] Salas R, (1979). International population Assistance: the 1st decade. A look at concept and policies which have guide the UNFPA in its first ten years. Pergamon.

[18] Sarre, P and Blunden, J. (1995).ed). Overcrowded world: population, resource and Environment. $1^{\text {st }}$ edition. Oxford.

[19] Seyoum, G/Sellasie (1990). Social structure and fertility in Addis Ababa: population and development bulletin. 1(2).

[20] Sewnet, Fantahun (2008). Determinants of family size preferences among currently married rural women in Hullet Ijju Enesie woreda, East Gojam zone of Amhara region. Thesis, AAU

[21] Tekeste, Negash (1996). Rethinking Education in Ethiopia. Nordiska, Africa Institute. Upsala.

[22] Todaro, M (1981). Economic Development in the third world. $2^{\text {nd }}$ edition. Longman.

[23] UNFPA(2008). Family planning and the Environment: stabilizing population would help sustain the planet. Fact sheet 3 http://www.unfpa.org/rh/planning/ mediakit/docs/sheet3.pdf, visited on January 4,2011

[24] USAID(2010). Making the Link: population, health and environment. population reference Beruea. USA http://www.prb.org/pdf10/bridge-environment .pdf, retrieved on February 7,2011

[25]Willy, M (2006). Communication about family planning on desired fertility among married people in Rwanda. Dissertation, University of KwaZulu-Natal http://researchspace.ukzn.ac.za/xmlui/bitstream/handl 
e/10413/1586/willy_Gasafari_Mpabuka 2006.pdf?se quence $=1$ visited on February 15, 2011

[26] Word Bank (1994). Enhancing women's participation in economic development. Washington, USA

[27] Wright, R (2008). Environmental Science: Towards sustainable future. $10^{\text {th }}$ edition. Pearson educational international. 